\title{
Precision Agriculture in Denmark and China: A Comprehensive Comparative Review with Policy Implications for China
}

\author{
Bornwell Mutale* Li Xianbao \\ College of Management, Ocean University of China, 238 Songling Road, Qingdao-China
}

\begin{abstract}
The global trend of a fast-growing population leading to a desperate need for food and an ultimate environmental degradation due to unsustainable agricultural practices calls for drastic measures. Precision Agriculture (PA), an approach that combines management, engineering, and information technology in agricultural production has the potential to address this global phenomenon. This paper reviewed the state of PA in Denmark and China. A comprehensive literature search was employed to first understand the general aspects that affect the adoption, motivation, and barriers to the adoption of PA, then acquire an insight into the state of PA between the two countries. Conclusions were drawn and recommendations made. It was observed that the rate of adoption by Chinese farmers is very low mainly due to the Chinese traditional small farm size and typically lack of motivation, awareness, and perceived quantifiable benefits to adopting PA. Contrary, PA in Denmark has been practiced for over 15 years and the adoption rate has since been magnificent. Most PA adopters have relatively large farms, mostly young, and have undergone formal training. The Danish farmers have adopted a wide range of PA Technologies in their diverse agricultural system and information on PA technologies and adoption trends has been made readily accessible. Though the initial high cost of using PA Technologies seems to be the most common and major barrier to adopt PA by both Chinese and Danish farmers, the state of PA in Denmark is worthy of emulating by China.
\end{abstract}

Keywords: Precision Agriculture (PA) technology, farmer, adoption, motivation, barrier, Denmark, China.

DOI: $10.7176 / \mathrm{JRDM} / 76-06$

Publication date:June $30^{\text {th }} 2021$

\section{Introduction}

The world population has been growing at a faster rate and as such, there has been great demand and pressure on limited resources such as food and land. According to the United Nations Food Agricultural Organization (FAO, 2011a) report, there were an estimated 925 million undernourished people by 2011 , representing about $13 \%$ of the total world's population. This number has however increased and the majority of this population live in rural areas where four out of five are farmers. FAO's report is consistent with the report by the International Fund for Agriculture Development (IFAD) and that of the World Food Program (WFP, 2011).

For instance, China's population has been predicted to rise to approximately 1.5 billion people by $2050(\mathrm{Li}$, 2006) and this will require the country to produce an additional 100 million tons of food per year to feed its fastgrowing population. In a bid to try and meet the Population's demand for food security, there has been more pressure on the limited arable land resource. This has contributed in most instances, to the degradation of the environment due to unsustainable agricultural practices such as over tillage, over-application of artificial fertilizers, insecticides, fungicides, herbicides, and other chemicals. These practices are not only harmful to the environment but also costly.

Therefore, due to the increasing input cost and decreasing commodity prices, farmers have ever been seeking ways of reducing these costs while increasing production, secure food supplies, and maintain environmental biodiversity. The object of such searches has not only been to acquire adequate quantities of agricultural produce but also quality, rigorous yet environmentally friendly as well as resource sustainable production. The desperate search has led to the discovery of Precision Agriculture (PA) which has now been practiced for slightly over 3 decades. PA seems to be the prospective alternative to improving productivity and profitability while reducing environmental impact and providing better risk management on farms. Gebbers and Adamchuk (2010) asserted that PA has great potential to contribute to agricultural production, as well as environmental protection and food security.

PA has the prospect to track agricultural produce from production through processing, storage, and retail. It provides added capability to respond to changing market conditions, ensure proper food nutrition and safety, and affect national and international policies related to food security. In a nutshell, PA is a management strategy that gathers, processes, and analyses temporal, spatial, and individual data and combines it with other information to support management decisions according to estimated variability for improved resource use efficiency, productivity, quality, profitability, and sustainability of agricultural production (Aubert et al., 2012; Mintert et al., 2016).

However, despite the known potential of PA to be the solution to the several problems faced by the agricultural sector, its adoption has been very slow (McConnell, 2019) by farmers from both developed and 
developing countries. The main objective of this paper is to compare the state of PA between Denmark and China and provide policy recommendations accordingly. The two countries are selected on the hypothesis that Denmark being a developed country and well vested in agriculture with more large-scale farmers might have more adopters of PA than China which is developing and mainly dominated by smallholder farmers. The remaining part of this paper is organized as follows; the next section presents the motivation and rationale of the study which explains the underlying motive for carrying out this study. This is followed by the data source and study approach section where the detailed methodology for the study is presented. After this, the findings and discussion section follow which forms the most essential part of this paper. Finally, the paper ends by presenting the conclusions and research prospects.

\section{Motivation and Rationale of the study}

In the early years of its emergence about 3 decades ago, the concept of PA focused on the study and management of spatial variability in crop production. It intended to match agricultural inputs and practices to localized conditions within a field to do the right thing, in the right place, at the right time, and in the right way (Pierce et al., 1994). Since then, other components of variability and other sectors of agriculture have been incorporated into the concept. Consequently, there have been trends in the correct and widely accepted definition of PA to try and suit its holistic approach. The most current and official definition of PA by the International Society for Precision Agriculture (ISPA) was adopted in July 2019. According to ISPA (2019), PA is a management strategy that gathers, processes, and analyses temporal, spatial, and individual data and combines it with other information to support management decisions according to estimated variability for improved resource use, efficiency, productivity, quality, profitability and sustainability of agricultural production. This definition is consistent with earlier definitions provided by various researchers including, (Fountas et al. (2016); the University of Sidney, Precision Agriculture Laboratory (2012); Adamchuk \& Gebbers (2010); Srinivasan (2006); Dobermann et al., (2004); US Code, House of Representatives (2002); McBratney \& Whelan, (2001); and Kitchen (1996)). PA comprises various technologies and farmers may adopt these technologies depending on their needs. According to Robertson et al., (2012) and Marote (2010), the most common and available PA technologies include Global Positioning Systems (GPS), Geographic Information Systems (GIS), yield monitors, near, far, and proximal remote sensors, and Variable-Rate Applicators (VRA). These technologies are either software or hardware, thus permitting for the obtainment of accurate information and timely engagements of best management decisions in specific areas of the field (Llumipanta, 2015).

As evidenced in its official definition, the notion of PA is based on the credit of spatial and temporal variability in agricultural production. This variability is accounted for in farm management with the target of increasing productivity and reducing environmental risks. PA, therefore, offers several advantages, among them, are the benefits highlighted by (Segarra, 2002) during his study of PA systems in Europe. They include; reduced production costs; increased overall yield; Better decision-making; reduced environmental impact; and efficiency improvement. Although the real economic benefits resulting from PA have proven difficult to measure (Lowenerg-Deoer, 1996), PA technologies offer farmers an opportunity of changing the distribution and timing of fertilizers and other agrochemicals based on spatial and temporal variability in a field. Farmers can, therefore, make an economic analysis based on the variability of crop yield in a field to achieve accurate risk assessments. The application of exact quantities at the appropriate time reduces the cost of agrochemicals, water, and labor inputs in crop production. It further evades the danger of excessive residue in soils and water hence reducing environmental contamination (Schumacher, 2000). Besides, the overall high yield reduces the cost per unit of output making PA an alternative to increasing profitability. Jochinke et al., (2007) further found that as time goes on and PA technologies become more and more available, their investment expenses have decreased significantly.

The precise selection of crop varieties, the application of exact types and doses of fertilizers, pesticides, and herbicides, and appropriate irrigation meet the demands of crops for optimum growth and development. This leads to yield increase, especially in areas or fields where uniform crop management was traditionally practiced. This is consistent with the view of (Pathak, 2003) who argued that PA has been helping many farmers worldwide to maximize the effectiveness of the crop inputs including seed quality, fertilizers, pesticides, and irrigation water. The advancement and increasing sophistication of PA machinery, tools and information, further help farmers to increase the efficiency in labor, land, and time resulting in economic, social, and environmental benefits (Nair, 2011). PA is thus more of the economic or efficient management of agricultural resources. It is a timely agricultural innovation especially in the $21^{\text {st }}$-century where the demand for food is increasing daily and the environment is fast degrading. Various studies have been done on PA technologies and their adoption trends, for instance; (Raghunandan et al., (2017), Robertson et al., (2012), Marote, (2010), Larson et al., (2008) and Roberts et al, (2004)) and many more studies that have been dedicated to PA technologies, benefits of PA and PA on specific crop varieties.

However, very little has been done to compare the state of affairs of PA between countries to emulate each 
other. Examples of these few kinds of research include (Li et al., (2019), Fountas (2005), and Roberts et al., (2002)). It is against this backdrop that this paper aims to conduct a comprehensive comparative review of the state of PA between Denmark and China to fill the gap in academic literature and also provoke policymakers. The specific objectives of the paper are to review the adoption of PA between the two countries; to review the motivation and barriers to the adoption of PA between the two countries and their implications, and then provide recommendations accordingly.

\subsection{A Synopsis of Denmark and China}

Denmark is located in the Northern part of Europe. It borders the Baltic Sea and the North Sea, on a peninsula north of Germany and includes two major islands, namely, Sjaelland and Fyn. Denmark has a total area of $43,094 \mathrm{~km}^{2}$ of which land accounts for $42,394 \mathrm{Km}^{2}$ whereas $700 \mathrm{~km}^{2}$ is water. Of this $42,394 \mathrm{~km}^{2}$ land, $54.02 \%$ is described as arable, $0.19 \%$ for permanent crops, and $45.79 \%$ for others. Most of Denmark consists of flat lands with very little elevation, except for the hilly central area on the Jutland Peninsula (World Atlas, 2017).

Agriculture is the main source of income for Denmark with a high export rate especially to countries such as Germany, the United Kingdom, Sweden, and China as the main markets. This is so because Denmark has an average population of 5.7 million people, but its food production is high enough to feed 15 million people. Almost two-thirds of the Danish area is agricultural land with wheat and barley as the chief crops grown. The agricultural sector contributes about $25 \%$ of the total Danish export of goods (Agriworker, 2019). Agriculture in Denmark has witnessed rapid technological development. The food sector's direct and indirect contribution to income formation was estimated at 110.6 billion Danish kroner in 2015 which translates to about 5.6\% of GDP (Danish Agriculture Agency, 2015). Denmark is thus the only country in the Baltic region with a net export of agricultural products, producing three (3) times the amount of food it needs for itself. This has been made possible by a good percentage of arable land and moderate climate which is favorable to agriculture. However, the country's extremely advanced technology and infrastructure in recent years are what have made it to be so productive. One of the notable technological advancements is the farmers' slow but steady shift to PA Technologies. PA in Denmark has been in practice for over 10 years (Pedersen, 2014), thus making Denmark a good choice for this study.

China, on the other hand, is located in East Asia with a total area of about 9.6 million $\mathrm{km}^{2}$ and is composed of mountains accounting for $33 \%$, plateau $26 \%$, valleys $19 \%$, plains $12 \%$, and hills $10 \%$. Arable land is only estimated at 110.0 million ha (FAO, 2011b). China is conventionally divided into four main agro-climatic zones according to (Wang et al., 1999). These are; the arid zone which is located chiefly in the inland river basins in the west and northwest; the semi-arid zone situated mainly in the upper and middle reaches of the Yellow river basin in central China; the semi-humid zone mainly in the North East subzone and the humid zone which lies in the south and southwest of the country.

China like Denmark is also an agricultural country, although the Chinese system is mainly characterized by small-scale family-run farms (Jiyun \& Cheng, 2002). Nevertheless, as opposed to Denmark's small population and having more agricultural production than its needs, China comprises one-fifth of the world's population and this increasing population has to be fed on its arable land while the nation's expanding cities are rapidly consuming arable land. It is estimated $(\mathrm{Li}, 2006)$ that by 2050 , China's population will reach approximately 1.5 billion and the country will need to produce an additional 100 million tons of food per year to meet the demand. However, by the same period, the country's yield production is projected to fall from $14 \%$ to $23 \%$ due to water shortages and other impacts like unsustainable agricultural practices. Therefore, the anticipated challenge of meeting food demand for the increasing population may have to be met by a paradigm shift from a traditional way of agricultural practices to modern sustainable practices, viz. PA technologies.

Therefore, the unique characteristics of Denmark and China gave further motivation to carry out this study. The findings of this study are important to the academic board of knowledge, policy-makers as well as farmers.

\section{Data source and study approach.}

To achieve the aim of the study, this paper applied a detailed literature review approach according to the guidelines by (Hart, 1999) and some insights from (Meyer, 2020 and; Kitchenham \& Charters, 2007). Peerreviewed articles were collected from various authentic sources such as science directhttps://www.sciencedirect.com/, Scopus - https://www.scopus.com/, google scholar- https://scholar.google.com/ and springer- https://link.springer.com/. Furthermore, related online reports and conference papers from reliable websites and other sources like the International Society for Precision Agriculture (ISPA)https://www.ispag.org/ and the USDA National Agricultural Library https://www.nal.usda.gov/main/ were utilized.

Keywords in this study included Precision Agriculture (Technologies) (A), Adoption (B), Motivation/drive (C), Barriers/challenges (D), Denmark (E), and China (F). Therefore, the search procedure employed to acquire the data was the combinations of the different sets of these keywords. This procedure is summarized in table 1. 
Table 1: Combination techniques of keywords for sourcing data.

\begin{tabular}{lcc}
\hline \multicolumn{1}{c}{ Keywords } & Combination of Keywords & Category \\
\hline (A) Precision & Agriculture & $\mathrm{A}+\mathrm{B}$ \\
(Technologies) & $\mathrm{A}+\mathrm{B}+\mathrm{E}$ & \\
(B) Adoption & $\mathrm{A}+\mathrm{B}+\mathrm{F}$ & \\
(C) Motivation/driver & $\mathrm{A}+\mathrm{C}$ & \\
(D) Barriers/challenges & $\mathrm{A}+\mathrm{C}+\mathrm{E}$ & \\
(E) Denmark & $\mathrm{A}+\mathrm{C}+\mathrm{F}$ & Category 2 \\
(F) China. & $\mathrm{A}+\mathrm{D}$ & Category 3 \\
& $\mathrm{A}+\mathrm{D}+\mathrm{E}$ & \\
& $\mathrm{A}+\mathrm{D}+\mathrm{F}$ & Category 4 \\
\cline { 2 - 3 } & $\mathrm{A}+\mathrm{E}$ & $\mathrm{A}+\mathrm{F}$ \\
\end{tabular}

Category 1 in table 1 embodies the search for publications that address the adoption of PA in general and Denmark/China in particular. Category 2 represents the search for publications that address motivation/drive for the adoption of PA while category 3 represents the search for publications that talk about barriers to the adoption of PA. Finally, category 4 depicts the search for publications that gives an overview of PA in Denmark and China.

To reach out for more data, a snowball tactic was employed. This made it possible to find and review some cited articles in a particular paper that closely related to the topic under review but were not found in the initial search.

Using the procedure presented in table 1, more than 1000 publications were found. However, strategies were put forth to refine the search and obtain more useful articles for the study. These strategies included skimming and scanning the abstracts, introductions, and the conclusions of the publications and restricting the search in the sources to the research keywords. The protocol of skim and scan was employed only for the first 20 publications of each search combination. Thus, the search was filtered to 240 potential publications plus 13 more publications that were obtained through a snowball procedure resulting in a total of 253 potential publications. These potential publications were fully and carefully read before the decision to adopt them for this study. After a complete and thorough reading, less than 100 publications were adopted that best fit the objective of this study. Furthermore, an approach of the ex-post and ex-ante theory was utilized to acquire an insight into the factors and/or the motivation that influenced those who already adopted PA Technologies (ex-post) and also an insight into the "intentions" to adopt the technologies for the would-be adopters of PA (ex-ante). This categorization of publications further facilitated the identification of the barriers/challenges to the adoption of PA and boosted the discussion of the topic between Denmark and China.

\section{Findings and Discussion.}

Since the inception of PA, researchers have worked very hard to try and discover the underlying factors that influence its adoption. Table 2 organizes some of the most outstanding ex-ante publications that were used in this review while table 3 contains the most suitable ex-post publications for this review. These articles try to answer the general question of the adoption, motivation, and barriers to the adoption of PA. Using the assertions of these publications and combining with PA studies that took place in the Danish and Chinese setup, a sounder discussion of the topic at hand is guaranteed. 
Table 2. Ex-ante Publications

\begin{tabular}{|c|c|}
\hline Author(s) & About the article \\
\hline Hudson and Hite (2003) & Highlights the willingness of farmers to pay for PA technologies. \\
\hline Folorunso and Ogunseye, (2008) & $\begin{array}{l}\text { Discusses the relationship between PA technology acceptance and } \\
\text { knowledge level of farmers. }\end{array}$ \\
\hline Marra et al. (2010) & $\begin{array}{l}\text { Outlines the demand and willingness of farmers to pay for PA } \\
\text { technologies taking cotton yield monitors as a model. }\end{array}$ \\
\hline Adrian et al. (2005) & Discusses the perception and attitude of farmers towards PA. \\
\hline $\begin{array}{l}\text { Rezaei-Moghaddam and Salehi } \\
\text { (2010) }\end{array}$ & $\begin{array}{l}\text { Researched the intention of agricultural experts towards PA } \\
\text { technologies. }\end{array}$ \\
\hline Hite et al. (2002) & $\begin{array}{l}\text { Researched the willingness to pay for water quality improvement taking } \\
\text { PA as a case. }\end{array}$ \\
\hline Schieffer and Dillon (2015) & $\begin{array}{l}\text { Outlines the effect of the perception of PA technologies on agro- } \\
\text { environmental policy }\end{array}$ \\
\hline Barnes et al. (2018) & $\begin{array}{l}\text { Studied the Influencing factors and incentives on the intention to adopt } \\
\text { PA technologies. }\end{array}$ \\
\hline Clark et al. (2018) & Proposes the framework of technology adoption in China. \\
\hline Aubert et al. (2012) & Highlights the decisions of farmers towards the adoption of PA. \\
\hline Yost et al. (2018). & Outlines the initiative to enhance the awareness of PA. \\
\hline Li et al. (2020) & $\begin{array}{l}\text { Develops and tests a hybrid model which combines the perceived need } \\
\text { for the technology. characteristics (PNTC) and the "Adapted Unified } \\
\text { Theory of Acceptance and Usage of Technology (AUT)" model. }\end{array}$ \\
\hline
\end{tabular}

Table 3. Ex-post Publications

\begin{tabular}{|c|c|}
\hline Author(s) & About the article \\
\hline Khanna (2001) & $\begin{array}{l}\text { Stated the sequential adoption of PA including location, human capital, } \\
\text { and farmer innovativeness. }\end{array}$ \\
\hline Tamirat (2018) & $\begin{array}{l}\text { Studied the main socio-economic determinants of adoption of PA in } \\
\text { Denmark and Germany. }\end{array}$ \\
\hline Fountas et al. (2005) & Outlined the experience of farmers using PA in Denmark and German. \\
\hline Paustian and Theuvsen (2017) & Researches on the adoption of PA by German farmers. \\
\hline Tey and Brindal (2012) & $\begin{array}{l}\text { Explains different factors that affect PA and presents the motivation for } \\
\text { adopting PA. }\end{array}$ \\
\hline Winstead et al. (2010) & Irvey about the adoption of PA technology. \\
\hline Higgins et al. (2017) & $\begin{array}{l}\text { About the factors that affect PA adoption and outline the motivation to } \\
\text { adopt PA. }\end{array}$ \\
\hline $\begin{array}{l}\text { Far and Rezaei-Moghaddam } \\
(2018)\end{array}$ & Survey about the factors that influence PA adoption. \\
\hline $\begin{array}{l}\text { Schimmelpfennig and Ebel } \\
\text { (2011) }\end{array}$ & $\begin{array}{l}\text { Provides an emphasis on the importance of Knowledge in PA and the } \\
\text { cost of PA. }\end{array}$ \\
\hline Melchiori et al. (2013) & the motivations for the adoption of PA. \\
\hline Watcharaanantapong et al. (2014) & $\begin{array}{l}\text { Researches PA adoption in cotton and highlights the advantages of PA } \\
\text { in cotton production. }\end{array}$ \\
\hline Pignatti et al. (2015) & $\begin{array}{l}\text { Outlines the driver to the adoption of PA including cost reduction, } \\
\text { availability of the technology, and technical know-how. }\end{array}$ \\
\hline Robertson et al. (2012) & $\mathrm{s}$, motivation, and constraints to the adoption of PA. \\
\hline Daberkow and McBride (1998) & Outlined the socioeconomic profile of farmers who adopted PA early. \\
\hline Fernandez-Cornejo et al. (2002) & $\begin{array}{l}\text { Outlines the relationship of farm size with the adoption of PA and } \\
\text { Genetically engineered crops. }\end{array}$ \\
\hline Isgin et al. (2008) & $\begin{array}{l}\text { Discusses the adoption and adoption intensity of various PA } \\
\text { technologies. }\end{array}$ \\
\hline Reichardt and Jürgens (2009) & Presents the adoption of PA and future perspective of PA in Germany. \\
\hline Larson et al. (2008) & $\begin{array}{l}\text { Outlines the factors affecting the adoption of PA, taking remote sensing } \\
\text { for variable-rate application of inputs in cotton production as a model. }\end{array}$ \\
\hline Roberts et al. (2004) & $\begin{array}{l}\text { States the factors that affect the adoption of PA, states the motivation to } \\
\text { adopt PA. }\end{array}$ \\
\hline
\end{tabular}


Daberkow and McBride (2003)

Roberts et al. (2002)

Walton et al. (2008)

D’Antoni et al. (2012)

Torbett et al. (2007)

Demattê et al. (2014)

Nair (2011)

Kendall et al. (2017)

Ofori and El-Gayar (2020) Rogers (2003).
Stated the various features that influence the awareness and adoption of PA in the USA.

Discusses how location characteristics influence the probabilities of adoption of PA among counties.

Outlines factors that motivate farmers to adopt PA and what causes other farmers to abandon PA.

Outlines the perception of farmers toward PA technologies.

Stated the perceived benefits of PA technologies in improving potassium and phosphorus efficiency in cotton.

Highlights the advantages of PA over conventional agriculture.

Researches on the application of PA in cotton production from an economic perspective.

Researches PA in China, outlining the barriers and motivations to its adoption.

Outlines the drivers and challenges of PA using a social media perspective.

Highlights the perception of farmers in innovation diffusion.

\subsection{General Factors that affect the adoption of PA Technologies.}

The papers in Tables 2 and 3 above have a varied perspective of PA adoption. Some papers had a holistic approach to the adoption of PA while others concentrated on one or a few factors that affect the adoption of PA. Others still targeted the factors that influence the adoption of specific PA technologies on specific crops and extrapolated their findings. Therefore, this section highlights several of the common aspects that stand out in the adoption, motivation, and barriers to the adoption of PA technology combining the ex-ante and ex-post publications. These aspects are characterized and summarized in figure 1 and explained thereafter.

Perception of the farmer: Farmer perception may be seen as their subjective assessment of PA innovation characteristics. Farmers need to be sure of the risks and expected gains of adopting the new technology. Rogers (2003) proposed in his finding some perceived characteristics of innovation including comparative advantage. Comparative advantage is oftentimes used to evaluate the advantage of the new technology or innovation over the already existing technology. One of the key comparative advantage factors concerning PA is its apparent profitability. Farmers never want to venture into something that would not bring them tangible returns. Therefore, according to Walton et al. (2008), the higher the perceived profitability of a PA technology, the higher the adoption ratio. Farmer perception is thus a very important factor in motivating or impeding farmers from adopting PA technologies.

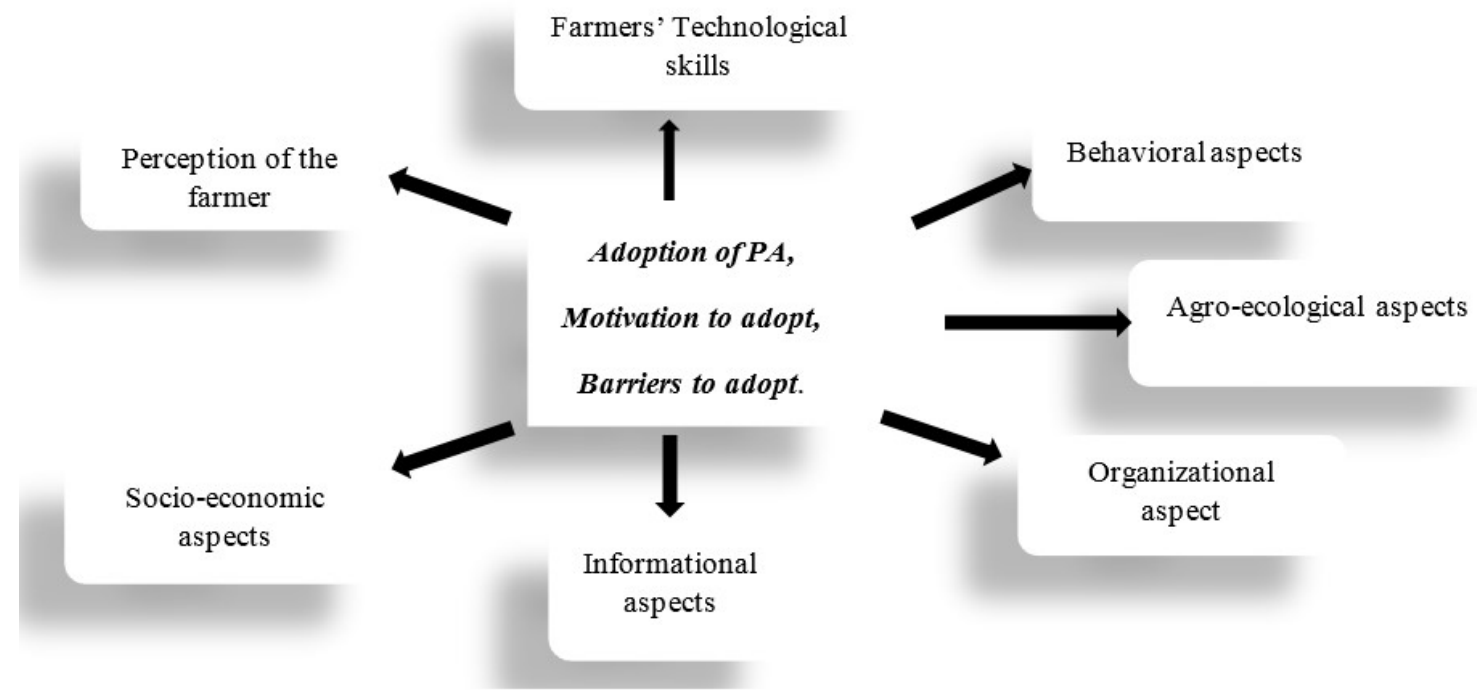

Figure 1. Characterized factors that affect the adoption of PA.

Farmers' Technological skills: Farmers' technological skills including computer literacy and the use of other technologies are core to the adoption of PA. Farmers who will adopt PA need to be computer literate due to the nature of operations of PA technologies which require more work to be done electronically. For this reason, 
Roberts et al. (2004) concluded that computer skill is an essential component of PA. His finding is consistent with the assertion of other researchers such as (Isgin et al. (2008) and Larson et al. (2008)) who argued that computer use has generally been a significant factor in the adoption of PA. Therefore, farmers' technological skills are an important motivator of PA adoption. It, therefore, settles that farmers who lack technological skills, especially computer skills are highly unlikely to adopt PA.

Agro-ecological aspects: Agroecological factors represent on-farm natural endowments as well as operational factors regarding the adoption of PA. While soil quality is the only natural endowment that significantly impacts the adoption of PA, land tenure, farm size and financial status are on-farm factors that have been found to have a significant impact on PA adoption (Isgin et al. (2008) and Khanna (2001).

Batte (2003) argued that Farm size represents economies of scale which is an important concern in any endeavor to attain high-level technologies. In his assertion which is consistent with the argument of Kutter (2011), farmers with farmland that is equal to or greater than 500ha are most likely to adopt PA. Feder et al. (1985) further added that farmers' motivation to adopt PA increases as their investment costs, informational costs, and other uncertainties increase. Therefore, farmers with large farms are more likely to adopt PA technologies because they can absorb costs and risks and utilize these factors to their advantage. This is also consistent with the conclusions of Adrian (2005), Walton et al. (2008), and Robertson et al. (2012).

For Land tenure, the findings of Roberts et al. (2004) suggest that farmers who own private farmlands are highly motivated to adopt PA because they are likely to manage their land more constructively. They are more likely to enjoy the benefits ensuing from their farm management and, so, increase the motivation for the adoption of PA. Besides, as pertains to financial status, farmers with greater capital have a greater capacity to adopt PA. Financial capability can enhance the competencies of the farmer via the acquirement of entrepreneurial as well as technological skills.

Socio-economic aspects: Age, education level, and farmer's experience in farming are among the socioeconomic aspects found to have a significant impact on the adoption of PA. For example, Batte et al. (1990) found age to be a significant explanatory factor, which has a negative relationship with the adoption of hightechnological practices, such as computers. Roberts et al. (2004) found that older farmers have shorter planning horizons, diminished incentives to change, and less exposure to PA technologies. On the other hand, Larson et al. (2008) revealed that younger farmers have a longer career horizon and are more technologically orientated. Therefore, farmer's age as pertains to PA adoption has wide-ranging results depending on other factors surrounding the farmer. Some factors such as computer literacy may mostly favor young farmers which may thus motivate them to adopt PA. Other factors like farming experience may favor older farmers in deciding to adopt PA.

Therefore, according to the assertion of Khanna (2001) and Adhikari et al. (2009), greater 'farming experience' oftentimes leads to a better knowledge of spatial variability in the field and operational efficiency in a way that makes farmers learn by doing. This means that farming experience may not be necessarily a significant positive factor for all PA technologies and so its impact is thus varied. While Isgin et al. (2008) found more experienced farmers may not feel the need to adopt PA, Daberkow \& McBride (2003) and (Khanna, 2001) found the aspect of farming experience to positively influence the decision to adopt PA.

On the Education level, Larson et al. (2008) argued about the need for PA adopters to possess high education level. He stated that farmers with higher educated levels are easily able to meet the human capital needs of PA technology execution. They include such things as extensive technological and informationally driven analytical skills and knowledge-based interpretation. Therefore, farmers with a high level of education are more likely to adopt PA.

Informational aspects: Successful transmission of any Innovation requires credible information which is useful and readily accessible. Oftentimes, credible information in agriculture is obtained from extension agents through extension services but human resources in extension service are usually not enough to provide farm by farm service. Therefore, Robertson et al. (2012) in their research noted that farmers who can hire private extension advisors due to the complexity of PA technologies are highly motivated to adopt PA. Furthermore, the adoption of PA is highly probable if the information provided by these extension sources is perceived to be beneficial.

Organizational aspects: Organizational aspects are seen to be trends that permit or restrict farmer's predisposition towards behavior change. Predominantly, development trends and farm location are found to significantly impact the adoption of PA. For instance, Isgin et al. (2008) argued that as arable land is gradually booked for the expansion of cities, farmers' need for transformation to more prolific farming practices also increases. This drives farmers under such organizational pressures to resort to PA. On the other hand, D'Emden et al. (2006) revealed that a range of natural resources has a significant effect on the decision of the farmer to adopt PA. This means that farmers with farms located in regions endowed with natural resources tend to be highly motivated to adopt PA. Though Location is a significant aspect, it has to be complemented by other factors like proper management. Two resource-rich farms though under similar production environments cannot 
be managed the same way by two different farmers.

Behavioral aspects: In most research, behavioral aspects have been used to signify the farmer's mindset. Lynne et al. (1988) asserted that when a new technology is incapable of providing immediate benefits, aspects that pertain to behavior tend to play a significant role in decision-making. Since PA provides a blend of environmental as well as economic benefits, Lamba et al. (2009) assumed that 'intention' is a precursor to the decision-making process of adopting PA. Owing to the finding of Ajzen (1991), behavior fairly depends on factors such as capital and time to determine the extent to which the farmer is prepared to execute the behavior. Farmers, therefore, need to be in constant control of their behavior because it is coherent with intentionality and intentionality has a significant effect on farmers' decision to adopt PA.

\subsection{State of PA in Denmark.}

PA has been practiced in Denmark for more than 15 years now. The early adopters started with yield monitoring and mapping and continued with variable rate application of mainly lime and to some extent nitrogen fertilizers (Pedersen, 2014). Since the inception of the concept of PA, Denmark has been one of the few countries in the world with consistency in gathering and documenting information on the state of affairs of PA. Pedersen (2014) in his research discovered that about 400 Danish farmers were using PA Technologies by 2004. This figure, however, has gone up, for example, two surveys were conducted on 6281 Danish farmers in 2017 and 5708 farmers in 2018 who farm on government land (Denmark Statistics, 2019). It was revealed from these national surveys that about $23 \%$ of Danish farmers used some sort of PA technologies by 2018. Among the PA technologies that were found to be in common use include Global Navigation Satellite Systems, sprayer section control, software for planning nitrogen applications, satellite and drone images as well as crop sensors. Of these technologies, Global Navigation Satellite Systems was the most frequently adopted of all the technologies. RealTime Kinematic (RTK) Global Positioning Systems (GPS) were used by about 19\% of the farms which translates into $57 \%$ of the total cultivated land. Adoption of these technologies was found to be most common on relatively large farms. This is consistent with the earlier report by (Danish Statistics, 2002), in which it was stated that land farmed by farmers using PA technologies in Denmark was large compared with the average farm size in 2000. This is further consistent with the assertions of Walton et al. (2008) and Robertson et al. (2012) on the need for large farms to smoothly execute PA technologies. The number of Danish farmers who use PA on large farms has since increased and by the end of 2019, approximately $80 \%$ of the Danish farmers who practiced PA farmed an area which is greater than 200 ha. However, several farmers with smaller farms also practice PA in Denmark and have adopted PA technologies that are suitable for their small farms.

Besides, Sprayer Section Control was also adopted by a good percentage of Danish farmers representing $14 \%$ of farms which covers about $39 \%$ of the total cultivated area by 2018 . In the same year, drones or satellite images were used by $4 \%$ of farms with $13 \%$ of cultivated area, and then Crop sensors were used by $2 \%$ of farms representing 7\% of the total cultivated area (Denmark Statistics, 2018). This enthusiasm in implementing PA technologies sets a good pace and impression for the new generation of Danish farmers. The adoption of various kinds of PA technologies gives even more advantages to the Danish agricultural production who for many years have been at the forefront of technological innovations. More interesting is the fact that PA technologies in Denmark are adopted by mostly young and educated farmers who have embraced the efficiency in production brought about by PA technologies. This embodies the importance with which Danish farmers attach to innovation to realize and maintain high-quality agricultural production.

The Danish farmers are thus generally quite optimistic about the increased profitability of PA. Their adoption rate is overwhelming and can be attributed in part to the formal education of most farmers and relatively young age who are keen to try new technologies. This is consistent with (DSTanalyse, 2019) and can also be supported by earlier assertions by Batte et al. (1990) and Larson et al. (2008). Moreover, about 60\% of the Danish farmers who use PA technology are said to experience a positive outcome on quite many factors such as lower consumption of pesticides, diesel or less working hours, etc. This benefit can be asserted to motivate more Danish farmers to adopt PA technologies.

The importance of consistent training in any new technology like PA cannot be undermined. Danish farmers seem to be doing well concerning PA education and this can be appreciated from the uninterrupted frontrunning in the use of various PA technologies. Figure 2 shows that farmers who undergo continuous training have it easy to adopt quite several PA technologies compared to those who do not regularly undergo training. Overall, those who undergo continuous training of some sort tend to adopt PA technologies twice as much compared to those who do not undertake continuous training. In figure 2, for almost all the PA technologies presented, the number of regularly trained farmers who adopt the technology is more than twice the number of non-trained farmers. Therefore, it can be asserted that continuous training in PA technologies or Agricultural Sciences is key in motivating farmers to adopt and execute PA. 


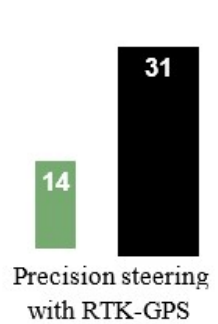

No continuous training

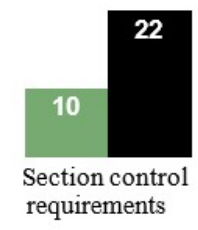

PA Technology

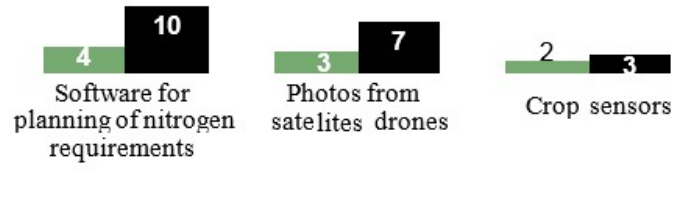

Figure 2: Showing Danish farmers' continuous and non-continuous training.

Source. adapted from Danish statistic, 2018.

However, despite showing great commitment and been front-runners in the adoption and execution of most PA technologies, some Danish farmers still face some impediments in adopting the technologies. Among the most notable barriers that Danish farmers face are summarized in figure 3.
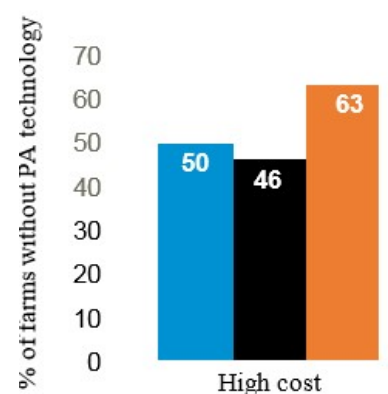

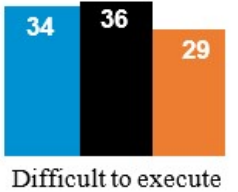

Difficult to execute

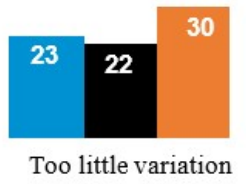

In the field

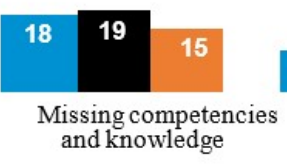

10

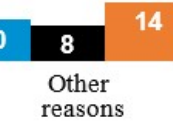

Barriers to adopt PA technologies

Figure 3. Barriers to the adoption of PA technologies experienced by some Danish farmers.

Source. adapted from Danish statistic, 2018.

From figure 3, cost, among other reasons is the most important barrier to the adoption of PA technologies especially by farmers with less than 50ha of farmland. Most PA equipment requires a substantial investment and so smallholders and/or relatively new farmers may find it costly to adopt PA. Similarly, most farmers with relatively smaller farms may not have the potential to contain the expenses that come with PA execution. Due to the small size of their farms, there would be no many variations in their fields so rendering the need for PA technology void. Though most farmers have come to understand the long-term economic benefit of PA, some farmers still find it hard to wait for the ambiguous benefits hence, evade adopting the technology altogether. Thus, Cost has the potential to highly bar farmers from adopting PA technologies. Besides cost, the hurdle in PA execution is what challenges most Danish farmers to adopt the technologies. The complexity of installation and operation limits the impatient and those farmers who lack certain competencies from trying the technologies.

However, since more Danish farmers have embraced PA and proved its efficient and high-quality production benefits, they have set a solid motivation for those who have not yet adopted PA on their farms. The utilization of PA technologies by Danish farmers has proved to enhance water usage, optimize seed sowing, enhance fertilizing, improve output and create high-quality food. This can be seen by a new cohort of Danish farmers who are now leaders in using satellites and drones to obtain a more efficient agricultural production. Therefore, the general state of PA in Denmark is overwhelming.

\subsection{State and implications of PA adoption in China.}

China comprises more than a quarter of the world's population which calls for drastic measures to ensure both high-quantity and high-quality agricultural production. It is estimated ( $\mathrm{Li}, 2006)$ that by 2050 when China's population is predicted to level off at approximately 1.5 billion, the country will need to produce an additional 100 million tons of food per year. This has significantly caused a lot of pressure on the Chinese agricultural system as asserted by Jiyun \& Cheng (2002) and it has led to the heavy use of inorganic fertilizers and other chemicals such as herbicides and pesticides. Therefore, PA could stand as a resolution to decrease heavy agrochemical use whereas concurrently easing the negative environmental impacts of agriculture and meeting the increasing food demand in China. However, the adoption of PA by most Chinese farmers is still low. For 
instance, a survey by Li et al. (2020) in three Chinese important agricultural provinces of Shandong, Henan, and Hebei revealed an average of $12 \%$ of the crop farmers to be using PA. Shandong Province had $13.7 \%$ while Hebei Province had 12\% and Henan Province had 10.6\% of the farmers using PA. Although most farmers have the willingness to adopt PA in the future, especially those who have had used PA before, several factors still prevent most Chinese farmers to adopt PA.

Unlike the Danish agricultural system with a good number of large-scale farmers, the Chinese agricultural system is characterized by small-scale family-run farms called the 'family responsible system' (Jiyun \& Cheng, 2002). These family-run farms are normally associated with diverse levels of mechanization, production scale, and farmer education, thus making it hard to apply PA technologies. This argument is consistent with Feder et al. (1985) who settled that farmers with large farms tend to adopt PA technologies more than farmers with smaller farms. Therefore, due to the traditional nature of agricultural practices on these smaller farms, PA technologies are considered inappropriate and superfluous. Farm size is one of the major barriers to the adoption of PA technologies by most Chinese farmers.

PA is still considered to be in its initial stages in China. According to Kendall et al. (2017), immediate paybacks of PA in China were noted to only benefit large farms, with no clear application benefits for family farms. Furthermore, Kendall and others noted that the financial risks associated with PA technology investment were a significant barrier to their adoption, with related costs assumed to be better suited to larger farms and prohibiting adoption by small farms. Besides, there is very little knowledge of PA technologies by most Chinese farmers because most of the small farms are managed by relatively older farmers. This can be attributed to ruralurban migration trends in which most younger people migrate to urban cities for greener pastures and so do not usually involve in farming. Most of the older majority lack formal education which translates into the low rate of PA awareness and its ultimate adoption. This is in line with the argument by Batte et al. (1990), who resolved that age has a significant influence on PA adoption with older age tending to have low adoption. Hence, relatively younger farmers even in China who have acquired higher levels of formal education (Adrian et al., 2005); those with relatively large farms; and those having a huge financial investment (Kutter et al., 2009) are believed to willingly adopt PA technologies. The particular high costs of PA technologies are furthermore the greater barrier to the adoption of PA by most small-scale farmers. They tend to feel demotivated because they cannot quantify the perceived benefits of adopting PA, thus, confirming the argument of Adrian et al. (2005).

Because of the low adoption rate of PA by Chinese farmers, most of them do not even perceive the technology to have higher-order risks. Neither does the cultural concept seem to affect the adoption of PA as noted in other cultural setups such as (Kutter et al., 2009). Therefore, the perceived need for PA characteristics and the Chinese farmers' perception of the advantages of PA are crucial for its adoption. Farmers are also keen on the efficiency, ease of use, and associated risks of the technology. Therefore, if reliable information about PA is not readily accessible, farmers' intention to adopt the technology can seldom be roused.

Some measures have already been put in place by the Chinese government to reinforce food security for its growing population. Even in PA, huge projects have been undertaken on the use of various PA technologies in China. For instance, the "PAFiC", Precision Agriculture for Family Farms in China, (PAFiC, 2016) which run from 2016-2019 was dedicated to technology innovation and pilot projects using PA technologies. However, despite the potential of PA technologies in ensuring high-quantity and quality of agricultural production, it is evident that the adoption of PA by most Chinese farmers is still considerably lower than in other countries like Denmark. Therefore, having reviewed the general factors that motivate and challenge the adoption of PA technologies and having reviewed the state of PA in Denmark as a model for China, this paper identified a few more things that need attention by agricultural policy-makers to enhance PA adoption in China. The recommendations are thus put forth as follows:

- Due to higher capital investment costs of PA technologies, many farmers have been prevented from adopting the technologies. Therefore, there is a need for the governments to subsidize some essential PA equipment by rising investment and support for rural communities;

- There is a need to involve farmers in the process of developing essential PA technologies. This will ensure the rightful technology for the right groups and could be the best way to integrate PA into the Chinese agricultural system thereby enhancing the adoption rate thereof;

- There is a fundamental need for simplified and affordable PA technologies to be developed, that may be better suited for the Chinese agricultural landscape, particularly concerning small and medium farms with greater agronomic variation over smaller areas;

- $\quad$ There is a need for the Chinese agricultural departments to encourage the young generation to get involved in agricultural innovations because young people are open-minded and are mostly ready to adapt to fast-changing technologies.

- There is a need to make PA education available to farmers through frequent workshops, seminars, and the like. Information about PA in general and PA technology adoption in particular need to be documented and made readily accessible to farmers. This will improve farmer's understanding of 
PA and finally boost interest to adopt the technologies.

Furthermore, the development of PA in China has a little deficiency in technology, land scale, and highquality labor force. The future development strategy of PA must be to build up an innovative technological system, adaptable technological application system, and multidisciplinary talent system. Therefore, according to the Chinese agricultural development characteristics, the technological stem of water-saving and fertilizer-saving PA should be developed shortly. The precision-equipped agriculture can be implemented firstly in the region where the equipped agriculture has already been developed. The big farms, which have large scales and high mechanization levels, may carry on the practice of the PA first. Further key points of PA development in China are necessary:

- Breaking the technical bottleneck- that is, enhancing the research of crop model, developing technique and information equipment, establishing watershed-based geographical information system and constituting demonstration regions of PA;

- Decreasing cost of technological production- break down the constraints of land concentration, promote moderate scale operation of agriculture, provide a diversified communication and cooperation platform for agriculture;

- Solving agricultural production problem- adopting a suitable pattern of technology application, adopting effective technology extension, establishing the technical standard, and so on.

The first stage to usher in PA in China must be the demonstration stage; the second stage will experiment with the demonstration work to expand to the large and state-run farms and the small-scale peasant farmers. Consequently, grasp large-scaled farms as the small size raises also, wanting to specially carry out the concept and methods of PA in the small-scaled peasant holders, and further investigate the regulation and the backlog experience; the third stage becomes "precision agriculture mode" of Chinese special features to experiment the demonstration foundation, and become part of the regional practical turn to turn with the industry.

\section{Conclusions}

The innovative use of PA technologies has the prospects of meeting an ever-increasing global demand for food while guaranteeing the sustainability of primary production. It can also open up many new markets, for instance, for more demanding and informed consumers, farmers can create their production chain for their produce. There are numerous technical, economic, and environmental prospects for PA. However, there are also numerous barriers for farmers, advisers as well as manufacturers of PA technologies because various procedures and decision support systems must be incorporated into the whole management system and the costs of gathering PA information are still relatively high. PA adoption in China is very low and a lot more things especially as pertains to policy have to be done to increase awareness and enhance its adoption. Denmark on the other hand boasts of being one of the few countries where information on PA technology and adoption trends is readily available. The major difference between the Danish and Chinese farmers with regards to PA technology adoption as revealed in this paper is the differences in farm size, farmer age, formal training, and awareness. While most Chinese farms are small to medium, often run by relatively old farmers, Danish farms are relatively large and often run by young farmers of whom most have some sort of formal and continuous training. Thus, making it easier for most Danish farmers to adopt the new technologies compared to their Chinese counterparts. Most Danish farmers have adopted several PA technologies and are now leaders in using different PA machinery. They have undertaken to set a roadmap for the new generation of agricultural productivity that combines management, engineering, and information technology. Finally, the Danish approach and attitude towards PA technology are worthy of emulating by China. Future studies should consider how various PA technologies can be incorporated on relatively small farms especially with regards to the majority of the Chinese farm setup. Empirical studies on the promotion of PA in developing countries across the world are also necessary as the world endeavor to attain Sustainable Development Goals without leaving anyone behind.

\section{Acknowledgment}

The authors are grateful to the anonymous reviewers for the review process and comments.

\section{Conflict of interest}

The authors declare no known conflict of interest.

Funding

This work did not receive any special funding.

\section{References}

Adhikari, A., Mishra, A. K., \& Chintawar, S., (2019). Adoption of technology and its impact on the profitability of young and beginning farmers: A quantile regression approach. Paper presented at the Southern Agricultural Economics Association Annual Meeting, Georgia, USA, (2009, January 31-February 3).

Adrian, A.M., Norwood, S.H. \& Mask, P.L., (2005). Producers' perceptions and attitudes towards precision agriculture technology, Comput Electon Agr. 48 256-77 https://doi.org/10.1016/j.compag.2005.04.004. 
Agriworker (2019). Agriculture in Denmark. Country information on Denmark. https://www.agriworker.eu/en/danmark/country-information-menu/agriculture-in-denmark

Ajzen, I., (1991). The theory of planned behavior. Organizational Behaviour and Human Decision Processes, 50(2), 179-211. https://doi.org/10.1016/0749-5978(91)90020-T.

Aubert, B.A., Schroeder, A., Grimaudo, J., (2012). IT as enabler of sustainable farming: An empirical analysis of farmers' adoption decision of precision agriculture technology, Decision Support Systems, Volume 54, Issue 1, 2012, Pages 510-520, ISSN 0167-9236, https://doi.org/10.1016/j.dss.2012.07.002.

B. Kitchenham, S. Charters (2007). Guidelines for performing systematic literature reviews in software engineering version 2.3 Engineering, 45 (4ve) p. 1051. http://doi=10.1.1.117.471\&rep=rep1\&type=pdf.

Barnes, AP., Soto, I., Eory, V., eta 1. (2018). Influencing factors and incentives on the intention to adopt precision agricultural technologies within arable farming systems. Environmental Science and Policy, 93, 66 - 74. https://doi.org/10.1016/j.envsci.2018.12.014.

Batte MT, Arnholt MW. (2003). Precision farming adoption and use in Ohio: case studies of six leading-edge adopters. Comput Electron Agric. 38:125-139. https://doi.org/10.1016/S0168-1699(02)00143-6.

Batte, M. T., Jones, E., \& Schnitkey, G. D., (1990). Computer use by Ohio commercial farmers. American Journal of Agricultural Economics, 72(4), 935-945. https://doi.org/10.2307/1242625.

Clark, B., Jones, J.D., Kendall, H., et al. (2018). A proposed framework for accelerating technology trajectories in agriculture: a case study in China[J]. Front. Agr. Sci. Eng., 5(4): 485-498. https://doi.org/10.15302/JFASE-2018244.

D’Antoni, J.M., Mishra, A.K., Joo, H. (2012). Farmers' perception of precision technology: The case of autosteer adoption by cotton farmers. Computers and Electronics in Agriculture, Pages 121-128. https://doi.org/10.1016/j.compag.2012.05.017.

D’Emden, F. H., Llewellyn, R. S., \& Burton, M. P. (2006). Adoption of conservation tillage in Australian cropping regions: An application of duration analysis. Technological Forecasting and Social Change, 73(6), 630-647. https://doi.org/10.1016/j.techfore.2005.07.003.

Daberkow, S.G., McBride, W.D. (1998). Socioeconomic Profiles of Early Adopters of Precision Agriculture Technologies J Agribus, 16 pp. 151-168. http://dx.doi.org/10.22004/ag.econ.90442.

Daberkow, S.G., McBride, W.D. (2003). Farm and Operator Characteristics Affecting the Awareness and Adoption of Precision Agriculture Technologies in the US. Precision Agriculture 4, 163- 177. https://doi.org/10.1023/A:1024557205871.

Danish Agricultural Agency, (2015). Ministry of Environment and food. https://eng.lbst.dk/agriculture/.

Danish Statistics (2002). Landbrug 2001, Denmark's Statistik.

Dobermann, A., Blackmore, B. S., Cook, S., \& Adamchuk, V. I., (2004). Precision farming: challenges and future directions. In New Directions for a Diverse Planet. Proceeding of 4th International Crop Sci. Congr. (pp. 1-19).

DSTanalyse, (2019). Precision farming: who uses it and what is the effect? Denmark statistic.

FAO. (2011a). 'The state of food security in the world', United Nations Food Agriculture Organization. Rome.

FAO. (2020). www.fao.org/in-action/plant-breeding/background/en/.

FAO. (2011b). Aquastat Country Profile - China. Food and Agriculture Organization of the United Nations (FAO). Rome, Italy

Feder, G., Just, R. E., \& Zilberman, D. (1985). Adoption of agricultural innovations in developing countries: A survey. Economic Development and Cultural Change, 33(2), 255-298.

Fountas, S., Aggelopoulou, K., \& Gemtos, T. A. (2016). Precision Agriculture. In Supply Chain Management for Sustainable Food Networks (pp. 41-65). Chichester, UK: John Wiley \& Sons, Ltd.

Fountas, S., Blackmore, S., Ess, D. et al. (2005). Farmer Experience with Precision Agriculture in Denmark and the US Eastern Corn Belt. Precision Agric 6, 121-141 https://doi.org/10.1007/s11119-004-1030-z.

Gebbers, R., Adamchuk, V.I. (2010). Precision agriculture and food security. Science 327 828-831.

Hart C. (1999). Doing a Literature Review: Releasing the Social Science Research Imagination. SAGE Publications Ltd; 1st edition (March 1, 1999).

Isgin, T., Bilgic, A., Forster, D. L., Batte, M.T. (2008). Using count data models to determine the factors affecting farmers' quantity decisions of precision farming technology adoption, Computers and Electronics in Agriculture, Pages 231-242, https://doi.org/10.1016/j.compag.2008.01.004.

ISPA (2019). International Society for Precision Agriculture, www.ispag.org/about/definition.

Jiyun, J. \& Cheng, J. (2002). Spatial variability of soil nutrients and site-specific nutrient management in the P. R China, Comput Electron Agr, 36 165-172. https://doi.org/10.1016/S0168-1699(02)00099-6.

Jochinke, D.C., Noonon, B.J., Wachsmann, N.G., Norton, R.M. (2007). The adoption of precision agriculture in an Australian broadacre cropping system-Challenges and opportunities, Field Crops Research, Volume 104, Issues 1-3, 2007, Pages 68-76, https://doi.org/10.1016/j.fcr.2007.05.016.

Kendall, H., Naughton, P., Clark, B., Taylor, J., Li, Z., Zhao, C. \& Frewer, L. (2017). Precision Agriculture in 
China: Exploring Awareness, Understanding, Attitudes and Perceptions of Agricultural Experts and EndUsers in China. Advances in Animal Biosciences, 8(2), 703-707. https://doi.org/10.1017/S2040470017001066.

Khanna, M., (2001). Sequential adoption of site-specific technologies and its implications for Nitrogen productivity: A double selectivity model. American Journal of Agricultural Economics. http://dx.doi.org/10.22004/ag.econ.21599.

Kitchen NR, Sudduth KA, Birrel S.J, Borgelt SC, (1996). Missourei precision agriculture research and education, Proceedings of the $3^{\text {rd }}$ International Conference of Precision Agriculture, 1996, Madison, WI. ASA/CSSA/SSSA. https://doi.org/10.2134/1996.precisionagproc3.c133.

Kutter, T., Tiemann, S., Siebert, R. et al. (2011). The role of communication and co-operation in the adoption of precision farming. Precision Agric 12, 2-17 https://doi.org/10.1007/s11119-009- 9150-0.

Lamba, P., Filson, G. \& Adekunle, B. (2009). Factors affecting the adoption of best management practices in southern Ontario. Environmentalist 29, 64 https://doi.org/10.1007/s10669-008-9183-3.

Larson, J.A., Roberts, R.K., English, B.C., et al. (2008). Factors affecting farmer adoption of remotely sensed imagery for precision management in cotton production. Precision Agric 9, 195-208. https://doi.org/10.1007/s11119-008-9065-1.

Li, W., Clark, B., Taylor, et al. (2020). A hybrid modelling approach to understanding adoption of precision agriculture technologies in Chinese cropping systems, Computers and Electronics in Agriculture, Volume 172, 2020,105305, ISSN 0168-1699, https://doi.org/10.1016/j.compag.2020.105305.

Li, Yuanhua. (2006). Strategies for coping with water scarcity in China.

Li, Z., Taylor, J., Frewer, et al. (2019). A comparative review of the state and advancement of Site- Specific Crop Management in the UK and China[J]. Front. Agr. Sci. Eng. 6(2): 116-136. https://doi.org/10.15302/JFASE-2018240.

Llumipanta E., Richard R., Armando N. (2015). Thesis (Master in Geographic Information Systems), Universidad San Francisco de Quito, Graduate College; Quito, Ecuador, 2015. B.S. thesis, Quito: USFQ, 2015. http://repositorio.usfq.edu.ec/handle/23000/4224.

Lowenberg-DeBoer, (1996). Economics of precision farming: payoff in the future. URL: http://pasture.ecn.purdue.edu/ mmorgan/PFI/pfiecon.html. Purdue University, IN, USA.

Lynne, G., Shonkwiler, J., \& Rola, L., (1988). Attitudes and farmer conservation behaviour. American Journal Agriculture.

Marote M.L. (2010). Agricultura de precisión. Ciencia y tecnología. doi.org/10.18682/cyt.v1i1.765.

McBratney, A. B., \& Whelan, B., (2001). Precision Ag. - Oz style. In First Australian Geospatial Information and Agriculture Conference (Vol. Sydney, Au, pp. 274-282). NSW Ag.

McConnell, M.D. (2019), Bridging the gap between conservation delivery and economics with precision agriculture. Wildl. Soc. Bull., 43: 391-397. https://doi.org/10.1002/wsb.995

Meyer, M.A, (2020). The role of resilience in food system studies in low- and middle-income countries. Global Food Security. 2020, 24, 100356. https://doi.org/10.1016/j.gfs.2020.100356.

Mintert, J., Widmar, D., Langemeier, M., Boehlje, M., Erickson, B., (2016). The challenges of precision agriculture: is big data the answer. In: Southern Agricultural Economics Association Annual Meeting, San Antonio, Texas. pp. 1-9. http://dx.doi.org/10.22004/ag.econ.230057.

Nair, S. (2011). Three essays on the economics of precision agriculture in cotton production. Ph.D. thesis, Texas Tech University. http://hdl.handle.net/2346/ETD-TTU-2011-05-1433. 2011-05.

Ofori, M., El-Gayar, O, (2020). Drivers and challenges of precision agriculture: a social media perspective. Precision Agric https://doi.org/10.1007/s11119-020-09760-0.

PAFiC (2016). Precision Agriculture for Family Farms in China "PAFiC" is joint funded by the funded by the UK-China Research and Innovation Partnership Fund (Newton Programme). http://gtr.rcuk.ac.uk/projects?ref=ST\%2FN006801\%2F1.

Pathak, H.; Prasad, S.; Bhatia, A.; Singh, S.; Kumar, S.; Singh, J.; Jain, M.C, (2003). Methane emission from rice-wheat cropping system in the Indo-Gangetic plain in relation to irrigation, farmyard manure, and dicyandiamide application. Agric. Ecosyst. Environ. p. 97, 309-316. https://doi.org/10.1016/S01678809(03)00033-1.

Pathak, H.S., Brown, P. \& Best, T. A (2019). systematic literature review of the factors affecting the precision agriculture adoption process. Precision Agric 20, 1292-1316. https://doi.org/10.1007/s11119- 019-09653-X.

Pedersen, S.M., Fountas, S., Blackmore, B. S., Gylling M., \& Pedersen, J. L. (2004). Adoption and perspectives of precision farming in Denmark, Acta Agriculture Scandinavian, Section B -Soil \& Plant Science, 54:1, 28, https://doi.org/10.1080/09064710310019757.

Raghunandan G. H., Namratha S. Y., Nanditha S. Y. and Swathi G., (2017). "Comparative analysis of different precision agriculture techniques using wireless sensor networks," 2017 4th International Conference on Electronics and Communication Systems (ICECS), Coimbatore, https://doi.org/10.1109/ECS.2017.8067853 
Reichardt, M., Jürgens, C. (2009). Adoption and future perspective of precision farming in Germany: results of several surveys among different agricultural target groups. Precision Agric 10, 73-94. https://doi.org/10.1007/s11119-008-9101-1.

Roberts, R. K., English, B. C., Larson, J. A., Cochran, R. L., Goodman, W. R., Larkin, S. L., et al., (2004). Adoption of site-specific information and variable-rate technologies in cotton precision farming. Journal of Agricultural and Applied Economics, 36(1), 143-158. http://dx.doi.org/10.22004/ag.econ.42943.

Roberts, R.K., English, B.C., Larson, J.A. (2002). Factors Affecting the Location of Precision Farming Technology Adoption in Tennessee. Extension Journal, Inc. ISSN 1077-5315. https://www.joe.org/faesjoe/joe/2002february/rb3.php.

Robertson, M.J., Llewellyn, R.S., Mandel, R. et al. (2012). Adoption of variable rate fertilizer application in the Australian grains industry: status, issues and prospects. Precision Agric 13, 181-199 https://doi.org/10.1007/s11119-011-9236-3.

Rogers, E. M. (2003). Diffusion of Innovations (5th ed.). New York: Free Press. Precision Agric.

Schieffer, J., Dillon, C. (2015). The economic and environmental impacts of precision agriculture and interactions with agro-environmental policy. Precision Agric 16, 46-https://doi.org/10.1007/s11119- 0149382-5.

Schumacher, J.A., Lindstrom, M., Schumacher, T. (2000). An analysis of tillage and water erosion over a complex landscape. Proceedings of Fifth International Conference on Precision Agriculture (CD), July 1619. Bloomington, MN, USA.

Segarra (2002). Precision Agriculture, the role of science. Dept. of Agric and Applied Ec. Texas Tech University.

Statistics Denmark (2018). Precision agriculture 2018. Business sectors www.dst.dk/nyt/30775 .

Tamirat, T.W., Pedersen, S.M., \& Lind, K.M., (2018). Farm and operator characteristics affecting adoption of precision agriculture in Denmark and Germany, Acta Agriculturae Scandinavica, Section B-Soil \& Plant Science, 68:4, 349-357, https://doi.org/10.1080/09064710.2017.1402949.

Torbett, J.C., Roberts, R.K., Larson, J.A. et al. (2007). Perceived importance of precision farming technologies in improving phosphorus and potassium efficiency in cotton production. Precision Agric 8, 127-137 https://doi.org/10.1007/s11119-007-9033-1.

U.S House of representatives. (2002). US code Title 7-Agriculture. Chapter 103-Agricultural research, extension, and education reform. Subchapter II-New agricultural research, extension, and education initiatives. Section 7623. (a) Definitions. Washington, USA: US.

University of Sidney, Precision Agriculture Laboratory, https://sydney.edu.au/agriculture/pal/about/what is precision agriculture.shtml.

Various. (2006). Handbook of Precision Agriculture. Principles and Applications. (A. Srinivasan, Ed.). binghamton, NY, USA: Food products press.

Walton, J., Lambert, D., Roberts, R., Larson, J., English, B., Larkin, S., . . . Reeves, J. (2008). Adoption and Abandonment of Precision Soil Sampling in Cotton Production. Journal of Agricultural and Resource Economics, 33(3), 428-448. http://www.jstor.org/stable/41220602.

Wang, R., Ouyang, Z., Ren, H., Min, Q. (1999). China water vision. The eco-sphere of water, environment, life, economy \& society. Research center for eco-environmental sciences, Chinese Academy of Sciences.

WorldAtlas,(2017).DenmarkGeography.https://www.worldatlas.com/webimage/countrys/europe/denmark/dklan d.htm.

Yost, M.A., Sudduth, K.A., Walthall, C.L. et al. (2019). Public-private collaboration toward research, education and innovation opportunities in precision agriculture. Precision Agric 20, 4-18 https://doi.org/10.1007/s11119-018-9583-4. 